\title{
Índice de Serviço das Calçadas (ISC)
}

\author{
Sidewalk Service Index (ISC)
}

\section{Otavio Henrique da Silva Generoso De Angelis Neto}

\section{Resumo}

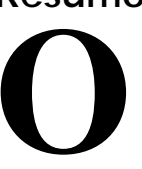

serviço oferecido pela infraestrutura de circulação de pedestres deve suprir a demanda local e proporcionar conforto e segurança a seus usuários. A questão é particularmente importante em cidades pequenas, para as quais, devido à ausência de transporte público e às pequenas distâncias, as viagens a pé constituem a base da mobilidade urbana. Esta pesquisa objetivou propor método de avaliação do nível de serviço (NS) de calçadas para cidades de pequeno porte, para disponibilizar recurso técnico à gestão desses espaços pelas municipalidades. O modelo elaborado e aplicado em São Tomé, PR, foi denominado Índice de Serviço das Calçadas (ISC), composto de dois índices que envolvem aspectos de qualidade do espaço (ISC qe $_{\text {) e de }}$ acessibilidade (ISC $\mathrm{I}_{\mathrm{a}}$ ). O método envolveu três etapas: análise técnica das calçadas (570 quadras), verificação da percepção do usuário por meio de pesquisa de opinião (355 munícipes) e atribuição dos níveis de serviço, variando de A (melhor situação) a F (pior situação), conforme resultados dos índices. Houve maior ocorrência do NS-F, principalmente nas áreas urbanas periféricas. Já níveis de serviço mais adequados (NS-A a NS-D) foram conferidos a 34,91\% das quadras. $\mathrm{O}$ modelo apresentou aplicabilidade adequada às cidades pequenas, havendo possibilidade de adaptações para utilização em maiores centros.

Palavras-chave: Avaliação de calçadas. Cidades de pequeno porte. Acessibilidade. Mobilidade urbana. Pedestre.

\section{Abstract}

The service offered by the pedestrian circulation infrastructure must meet local demand, providing comfort and safety to its users. This issue is particularly important in small towns, where, due to the lack of public transport and the short distances, walking is the basis of urban mobility. The aim of this research study was to propose method of evaluation of the Level-of-Service (LoS) of sidewalks in small urban centers, aiming to provide a technical resource to the management of these spaces by Municipalities. The model developed and applied in São Tomé, Paraná, Brazil, was called the Sidewalks Service Index (ISC in Portuguese), consisting of two indices that involve aspects of Space Quality and Accessibility (ISC $C_{q e}$ and ISC $C_{a}$ in Portuguese). The method involved three steps: technical

${ }^{1}$ Otavio Henrique da Silva ${ }^{1}$ Universidade Federal de São Carlos São Carlos - SP - Brasil

${ }^{2}$ Generoso De Angelis Neto ${ }^{2}$ Universidade Estadual de Maringá Maringá - PR - Brasil

Recebido em 30/05/17 Aceito em 08/04/18 analysis of the sidewalks (570 stretches), verification of users' perceptions by means of opinion polls (355 citizens) and assignment of Service Levels, varying from A to F (worst situation), according to results of the indices. There was a higher occurrence of LoS F, mainly in the peripheral urban areas. The most adequate Levels-of-Service (LoS A to D) were assigned to $34.91 \%$ of the stretches. The proposed model presented adequate applicability to small towns, with adaptations possible for use in larger centers.

Keywords: Evaluation of sidewalks. Small towns. Accessibility. Urban mobility. Pedestrian. 


\section{Introdução}

A falta de planejamento e a ausência de parâmetros para a execução e a manutenção de calçadas podem vir a ocasionar problemas para a caminhabilidade nas cidades, prejudicando a acessibilidade e o nível de serviço que esses espaços devem oferecer para que as viagens a pé possam ser executadas com conforto e segurança, e se configurar como alternativa viável aos demais modos de transporte.

Essa temática tem relevância principalmente em centros urbanos menores, tendo em vista que as pequenas distâncias a serem vencidas e a inexistência de transporte público corroboram para que as caminhadas arrimem a base da mobilidade urbana local.

Os instrumentos capazes de analisar o serviço das calçadas de uma urbe, juntamente com a base da normatização legal e técnica, são interessantes para se determinar a adequabilidade que tal infraestrutura proporciona aos usuários e, concomitantemente, constituir ferramenta para o adequado planejamento da circulação urbana, indicando a necessidade de se realizarem intervenções, bem como de definir quais fatores devem ser levados em conta para o projeto de novos ambientes visando à melhoria contínua do espaço urbano.

Quanto às normas técnicas, destaca-se a ABNT NBR 9050 (ABNT, 2015), a qual apresenta parâmetros relacionados à acessibilidade em áreas externas, cuja aplicabilidade estende-se aos espaços públicos de circulação. Dessa maneira, são definidas as propriedades que as calçadas devem apresentar para que sejam rotas acessíveis. Tais especificações, além de garantir a acessibilidade na urbe, são importantes para a melhoria do ambiente como um todo, ou seja, a aplicação dessa norma influencia diretamente o nível de serviço dos espaços para pedestres.

Com base nos métodos avaliadores já elaborados, verifica-se que os primeiros esforços despendidos para a qualificação dos espaços caminháveis deramse por meio de abordagens exclusivamente quantitativas e destinadas a espaços com grandes demandas de fluxo. Nesse contexto, o serviço da calçada seria relacionado a indicadores de operação de pedestres, tal como se constata nos modelos de Fruin (1971), da CET (COMPANHIA..., 1978), de Polus, Schofer e Ushpiz (1983) e do Highway Capacity Manual (HCM) (TRANSPORTATION..., 2010), publicado desde 1985.

Contudo, vista a complexidade da interação do pedestre com o espaço, a qual não se resume apenas à capacidade da via, Mori e Tsukaguchi (1987), Sarkar (1993), Khisty (1994) e Dixon (1996) apontaram a importância de aspectos qualitativos na experiência do transeunte, notadamente no que diz respeito a agradabilidade, conforto, conveniência, segurança de tráfego e seguridade. Baseando-se em tais pesquisas e nos sistemas de avaliação propostos, Ferreira e Sanches (2001) propuseram um método de qualificação dos espaços caminháveis (Índice de Qualidade das Calçadas IQC). Seguindo princípios metodológicos semelhantes, por meio de sistemas de pontuação, e fundamentando-se em trabalhos como os de Kockelman et al. (2000) e de Oeda, Sumi e Vandebona (2003), Ferreira e Sanches (2005) formularam um indicador focado em aspectos dimensionais e construtivos (Índice de Acessibilidade - IA).

Os modelos de Ferreira e Sanches (2001, 2005), já estudados por outros pesquisadores (KEPPE JÙNIOR, 2007; CORREIA, 2015; ALVES, 2015), têm relevância na medida em que integram diferentes aspectos relacionados às caminhadas, adaptados à realidade brasileira, além de considerarem a opinião do usuário. Contudo, sendo esses instrumentos desenvolvidos com base no contexto urbano de cidades médias, a aplicação em municípios pequenos pode incorrer em resultados imprecisos. Isso pode complicar sua aplicação justamente em locais em que os deslocamentos são realizados majoritariamente a pé, como é o caso da cidade de São Tomé, localizada no noroeste paranaense.

Mesmo se verificando os índices desenvolvidos mais recentemente, observam-se tentativas de quantificação do serviço de calçadas com base nas características de centros maiores, como é o caso de Talavera-Garcia e Soria-Lara (2015), Kadali e Vedagiri (2015) e Asadi-Shekari, Moeinaddini e Shah (2015), os quais desenvolveram modelos de qualificação com base nos modelos urbanos de Granada (Espanha), de Bombaim (Índia) e de Singapura.

Nesse sentido, o aprimoramento de métodos avaliadores do nível de serviço da infraestrutura pedonal em pequenos centros torna-se profícuo na medida em que eles atestam, ou não, a viabilidade das caminhadas como modo de transporte eficiente, seguro e com maior confiabilidade. Tais resultados podem indicar eventuais intervenções urbanísticas necessárias à garantia da acessibilidade nas cidades e, concomitantemente, à promoção da equidade nas condições de mobilidade dos cidadãos. Sendo assim, o objetivo desta pesquisa foi propor método de avaliação do nível de serviço de calçadas para cidades de pequeno porte. 


\section{Método}

O nível de serviço (NS) das calçadas da cidade de São Tomé foi determinado por meio do resultado de um índice destinado às cidades pequenas, o qual foi elaborado visando oferecer apoio à gestão técnica de espaços caminháveis. O modelo baseia-se nas metodologias de Ferreira e Sanches (2001) e de Ferreira e Sanches (2005), bem como nas indicações da ABNT NBR 9050:2015 (ABNT, 2015). O método contempla três etapas:

(a) avaliação técnica das calçadas por meio da atribuição de graus de qualidade para os fatores determinantes a seu nível de serviço;

(b) determinação da importância relativa dos parâmetros de qualificação com base nas preferências dos usuários; e

(c) avaliação final do nível de serviço com base no Índice de Serviço das Calçadas (ISC).

\section{Área de estudo}

Visando à elaboração e aplicação do método de análise das calçadas indicado a municípios de pequeno porte, com até 20.000 habitantes, a pesquisa foi realizada em São Tomé, PR, que possui população estimada para 2018 de 5.693 habitantes (INSTITUTO..., 2018).

O município localiza-se nas Regiões Geográficas Imediata de Cianorte e Intermediária de Maringá (INSTITUTO..., 2017), e conta com área territorial de $218,623 \mathrm{~km}^{2}$ (INSTITUTO..., 2018). A malha viária urbana do município possui aproximadamente $27 \mathrm{~km}$, sendo sua localização no território demonstrada na Figura 1. Tratando-se de indicadores sociais, o município possui Índice de Desenvolvimento Humano municipal (IDHM) de 0,725 (alto) e Índice Gini de 0,3863 (INSTITUTO..., 2013). A taxa de homicídios para cada 100.000 habitantes na Região Imediata que o município de São Tomé está inserido foi de 14,1 em 2014 (INSTITUTO..., 2016).

Figura 1 - Localização da malha urbana de São Tomé, PR

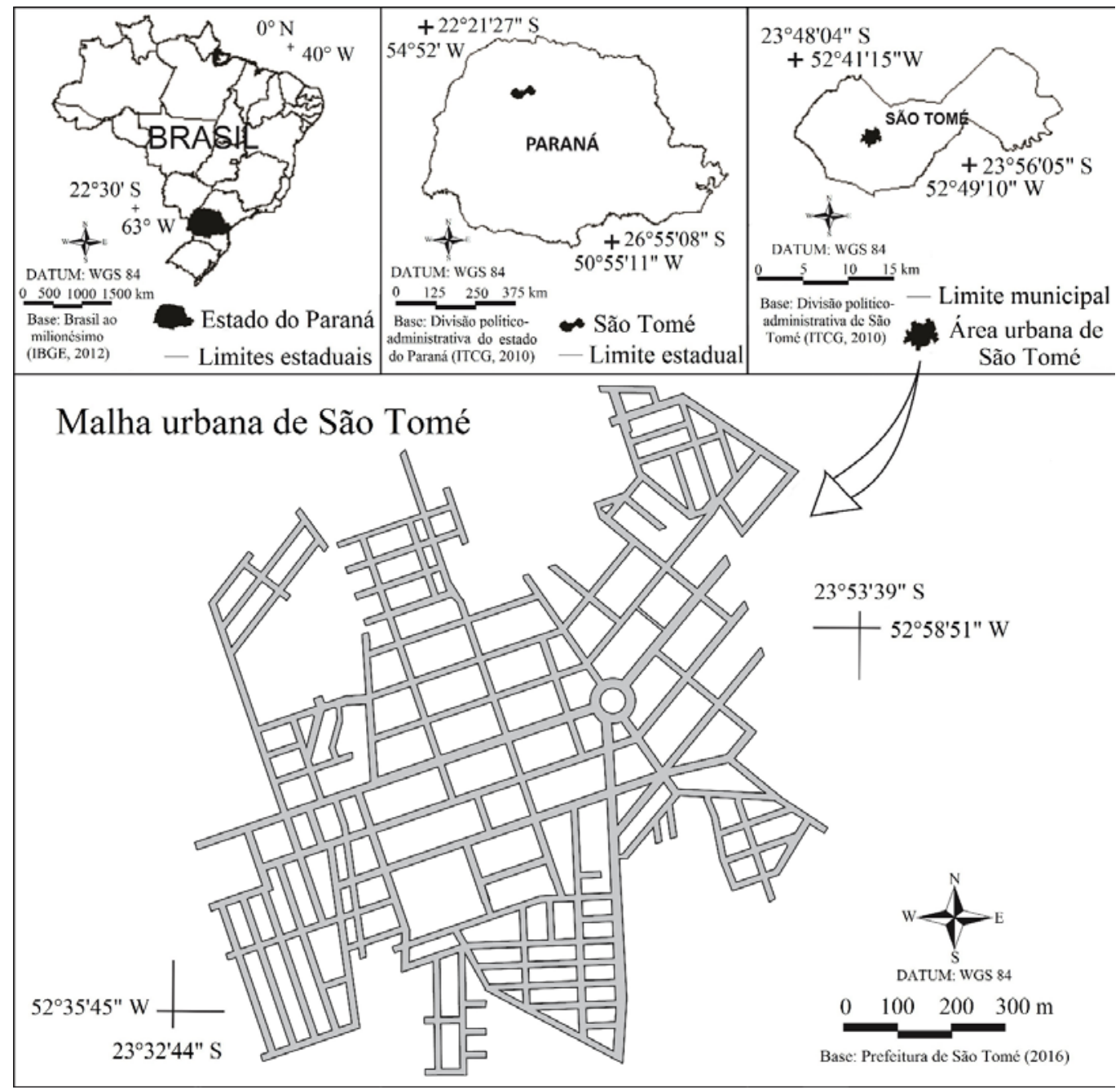




\section{Avaliação técnica das calçadas}

Conforme estudos e normatização definidos como base para o método proposto, definiram-se dez variáveis de qualificação para a composição do Índice de Serviço das Calçadas (ISC), sendo estas divididas em dois grupos (Quadro 1). O grupo de qualidade do espaço relaciona variáveis que conferem condições de segurança e de agradabilidade à viagem; já o grupo de acessibilidade é conexo a aspectos dimensionais do pavimento associados a possível interferência física no deslocamento das pessoas.

As variáveis foram escolhidas de modo que sua mensuração fosse prática, sem a necessidade da utilização de técnicas de quantificação complexas, bem como que houvesse relevância à dinâmica de cidades pequenas. Para tanto, definiu-se um sistema de escores correspondente a uma escala de valores, em unidades compatíveis entre si, representados por um intervalo de 0 a 5 pontos, havendo equivalência para com uma escala do NS, variando de 0 (péssimo) até 5 (excelente).

$\mathrm{Na}$ avaliação realizada pelo pesquisador foram atribuídos escores conforme cenário detectado em cada quadra, com o escore atribuído conforme a condição mais crítica presente em qualquer ponto ou área ao longo de sua extensão. Nesta pesquisa considera-se quadra o segmento entre as interseções (esquinas) do quarteirão, o qual corresponde ao espaço formado pelos cruzamentos, ou entroncamentos, de ao menos três arruamentos (Figura 2).

A escolha dos dias e horários para realização da análise técnica foi em função das características específicas de cada variável. Para análise da variável seguridade, por exemplo, a qual é influenciada pelo sistema de iluminação público, foi necessária a avaliação em período noturno. Os trabalhos de atribuição de escores ocorreram durante 31 dias no período de 2 de fevereiro até 31 de maio de 2016, das $8 \mathrm{~h}$ às $21 \mathrm{~h}$.

\section{Avaliação das variáveis de qualidade do espaço}

Neste grupo, a variável segurança (Quadro 2) contempla questões relacionadas à segurança de tráfego; construção e manutenção (Quadro 3) reúne informações quanto ao tipo de revestimento e sua conservação; seguridade (Quadro 4) leva em consideração a percepção do pesquisador em relação a questões referentes ao policiamento, à presença de pedestres e à iluminação noturna; atratividade (Quadro 5) remete à preocupação estética dos espaços e edificações, de forma a contribuir para a melhoria da paisagem; e arborização da calçada (Quadro 6) que é influenciada pelas características inadequadas das árvores presentes ao longo dos caminhos para pedestres.

\section{Quadro 1 - Grupo de variáveis relacionadas à qualidade do espaço e à acessibilidade}

\begin{tabular}{|c|c|c|}
\hline Grupo & Variável & Condição avaliada \\
\hline \multirow{5}{*}{ 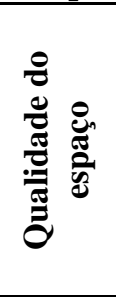 } & Segurança & Conflito entre pedestres e veículos \\
\hline & Construção e manutenção & Material utilizado e estado de conservação do pavimento \\
\hline & Seguridade & $\begin{array}{l}\begin{array}{l}\text { Vulnerabilidade do pedestre a ações de pessoas mal- } \\
\text { intencionadas }\end{array} \\
\end{array}$ \\
\hline & Atratividade & Agradabilidade estética visual do meio \\
\hline & Arborização da calçada & $\begin{array}{l}\text { Adequabilidade técnica das espécies à composição arbórea nas } \\
\text { calçadas }\end{array}$ \\
\hline \multirow{5}{*}{ 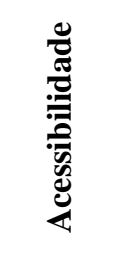 } & Largura efetiva & Faixa livre disponível \\
\hline & Sinalização e rampas & Existência de faixas de pedestres e rampas nas travessias \\
\hline & Inclinação longitudinal & Variação do perfil do pavimento no sentido longitudinal \\
\hline & Inclinação transversal & Variação do perfil do pavimento no sentido transversal \\
\hline & Desníveis & Existência de desníveis e degraus ao longo do trajeto \\
\hline
\end{tabular}


Figura 2 - Representação de quadras e quarteirão na área urbana

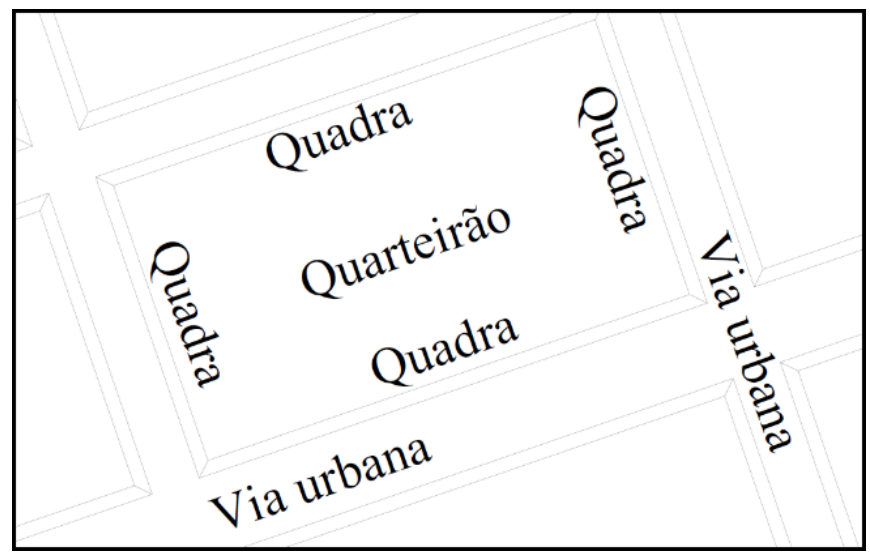

Quadro 2 - Sistema de pontuação para segurança

\begin{tabular}{|c|l|}
\hline Escore & \multicolumn{1}{|c|}{ Cenário } \\
\hline 5 & $\begin{array}{l}\text { Área de circulação de pedestres em nível diferente ao leito carroçável, situação sem } \\
\text { conflitos }\end{array}$ \\
\hline 4 & $\begin{array}{l}\text { Área de circulação de pedestres em nível diferente ao leito carroçável, presença de guias } \\
\text { rebaixadas para acesso de veículos em poucos pontos; número de guias rebaixadas igual ou } \\
\text { inferior ao número de lotes da quadra, situação possivelmente conflitante }\end{array}$ \\
\hline 3 & $\begin{array}{l}\text { Área de circulação de pedestres em nível diferente ao leito carroçável, presença de guias } \\
\text { rebaixadas para acesso de veículos em muitos pontos; número de guias rebaixadas superior } \\
\text { ao número de lotes da quadra, situação possivelmente conflitante }\end{array}$ \\
\hline 2 & $\begin{array}{l}\text { Área de circulação de pedestres em nível diferente, ou não, ao leito carroçável, acesso de } \\
\text { veículos em grandes extensões, situação possivelmente conflitante }\end{array}$ \\
\hline 1 & $\begin{array}{l}\text { Área de circulação de pedestres bloqueada, circulação realizada no leito carroçável, situação } \\
\text { muito conflitante }\end{array}$ \\
\hline 0 & $\begin{array}{l}\text { Área de circulação de pedestres inexistente, assim os pedestres têm de disputar a faixa de } \\
\text { rolamento com os veículos, situação muito conflitante }\end{array}$ \\
\hline
\end{tabular}

Quadro 3 - Sistema de pontuação para construção e manutenção

\begin{tabular}{|c|l|}
\hline Escore & \multicolumn{1}{c|}{ Cenário } \\
\hline 5 & $\begin{array}{l}\text { Pavimento com revestimento em material adequado, firme, antiderrapante, não trepidante, } \\
\text { com irregularidades e defeitos recuperados, manutenção adequada }\end{array}$ \\
\hline 4 & $\begin{array}{l}\text { Pavimento com revestimento em material inadequado, pouco rugoso, antiderrapante, } \\
\text { trepidante, com irregularidades e defeitos recuperados, manutenção adequada }\end{array}$ \\
\hline 3 & $\begin{array}{l}\text { Pavimento com revestimento em material inadequado, derrapante, com irregularidades e } \\
\text { defeitos recuperados, manutenção adequada }\end{array}$ \\
\hline 2 & $\begin{array}{l}\text { Pavimento com revestimento em condições inadequadas, superfície apresentando } \\
\text { irregularidades e defeitos, dificuldade na utilização da calçada, falta de manutenção }\end{array}$ \\
\hline 1 & Pavimento sem revestimento, solo exposto ou grama, dificuldade na utilização \\
\hline 0 & Calçada inexistente ou inutilizável pela precariedade do pavimento \\
\hline
\end{tabular}

\section{Quadro 4 - Sistema de pontuação para seguridade}

\begin{tabular}{|c|l|}
\hline Escore & \multicolumn{1}{|c|}{ Cenário } \\
\hline 5 & Ambiente com presença usual de pedestres, policiamento frequente e boa iluminação \\
\hline 4 & Ambiente com presença usual de pedestres, policiamento menos frequente e boa iluminação \\
\hline 3 & Ambiente com presença de pedestres, policiamento menos frequente e iluminação aceitável \\
\hline 2 & Ambiente com presença de pedestres, policiamento esporádico e iluminação deficiente \\
\hline 1 & Ambiente com presença eventual de pedestres, policiamento esporádico e iluminação deficiente \\
\hline 0 & Ambiente sem presença de pedestres, policiamento e iluminação \\
\hline
\end{tabular}




\section{Quadro 5 - Sistema de pontuação para atratividade}

\begin{tabular}{|c|l|}
\hline Escore & \multicolumn{1}{|c|}{ Cenário } \\
\hline 5 & $\begin{array}{l}\text { Calçada de acesso a espaços bem cuidados destinados à recreação e convivência coletiva ou } \\
\text { preservação ambiental, como praças e unidades de conservação ambiental }\end{array}$ \\
\hline 4 & $\begin{array}{l}\text { Calçada de acesso a espaço comercial, industrial e residencial dotado de preocupações } \\
\text { estéticas, como fachadas permeáveis, jardins à vista e vitrines atraentes }\end{array}$ \\
\hline 3 & $\begin{array}{l}\text { Calçada de acesso a espaço comercial, industrial e residencial sem preocupações estéticas, } \\
\text { havendo muros altos e fachadas impermeáveis }\end{array}$ \\
\hline 2 & $\begin{array}{l}\text { Calçada de acesso a espaço pouco atrativo, destinado a uso comercial e industrial de grande } \\
\text { porte, havendo poucos acessos à calçada }\end{array}$ \\
\hline 1 & $\begin{array}{l}\text { Calçada de acesso a espaço sem quaisquer preocupações estéticas, com construções com } \\
\text { acesso precário ou inexistente à calçada }\end{array}$ \\
\hline 0 & Calçada inadequada à utilização, ocorrência de resíduos e vegetação alta na calçada \\
\hline
\end{tabular}

\section{Quadro 6 - Sistema de pontuação para arborização da calçada}

\begin{tabular}{|c|l|}
\hline Escore & \multicolumn{1}{|c|}{ Cenário } \\
\hline 5 & Todos os indivíduos da arborização da calçada sem restrições técnicas, legais e ambientais \\
\hline 4 & $\begin{array}{l}\text { Indivíduos da arborização da calçada sem restrições técnicas, legais e ambientais com } \\
\text { ocorrência a partir de 66\% e inferior a 100\% }\end{array}$ \\
\hline 3 & $\begin{array}{l}\text { Indivíduos da arborização da calçada sem restrições técnicas, legais e ambientais com } \\
\text { ocorrência a partir de 33\% e inferior a 66\% }\end{array}$ \\
\hline 2 & $\begin{array}{l}\text { Indivíduos da arborização da calçada sem restrições técnicas, legais e ambientais com } \\
\text { ocorrência superior a 0\% e inferior a 33\% }\end{array}$ \\
\hline 1 & Inexistência da arborização ao longo da calçada \\
\hline 0 & Todos os indivíduos da arborização da calçada com restrições técnicas, legais e/ou ambientais \\
\hline
\end{tabular}

Neste estudo, para a atribuição de escores para arborização da calçada (Quadro 6), foram consideradas inadequadas tecnicamente as características vegetais incompatíveis com rotas acessíveis (ABNT, 2015), sendo elas sistema radicular com potencial de afloramento, arquitetura natural com potencial de interferência na faixa livre de circulação, desprendimento de frutos grandes e carnosos ou em grandes quantidades, toxicidade e estruturas pontiagudas. Tais características foram levantadas por meio de consulta de material do Herbário da Universidade Tecnológica Federal do Paraná - campus Campo Mourão (HCF). Foram inventariados os exemplares vegetais de porte arbóreo, ou conduzidos para tal, incluindo palmeiras (Arecaceae) e arbustos, sendo contabilizados todos os indivíduos com altura superior a 1,0 m presentes ao longo das calçadas de São Tomé.

Para averiguação da conformidade legal e ambiental, foram contemplados dispositivos normativos que impedem a utilização de espécies no espaço urbano analisado, destacando-se aquelas com comportamento exótico invasor, característica que influencia negativamente o ecossistema local e, portanto, a urbanidade como um todo.

Cita-se que essa avaliação pode ser útil ao planejamento da arborização viária municipal tendo em vista que, identificando-se as espécies inadequadas, se torna possível embasar a adequada tomada de decisão referente à substituição de exemplares arbóreos. Aponta-se que, a depender dos fins do gestor urbano, podem ser alteradas as características utilizadas nesta análise, desde que adequadamente embasadas.

\section{Avaliação das variáveis de acessibilidade}

Quanto às variáveis de acessibilidade, a largura efetiva (Quadro 7) contempla a faixa livre disponível para a caminhada; sinalização e rampas na travessia (Quadro 8) leva em conta a existência de rampas de acesso nas interseções e demarcação de faixas de travessias de pedestres; inclinação longitudinal (Quadro 9) e inclinação transversal (Quadro 10) correspondem ao alinhamento junto ao greide em seus respectivos perfis; e desníveis (Quadro 11) abrange desnivelamentos e degraus no piso.

\section{Importância relativa das variáveis de qualidade do espaço e de acessibilidade}

De modo a associar o serviço das calçadas às demandas dos munícipes, a análise técnica foi submetida à ponderação pela percepção dos 
usuários locais. Foram aplicados questionários a uma amostra estatisticamente representativa da população urbana para conhecer o perfil populacional e extrair as informações pertinentes à definição dos pesos das variáveis.

\section{Quadro 7 - Sistema de pontuação para largura efetiva}

\begin{tabular}{|c|l|}
\hline Escore & \multicolumn{1}{|c|}{ Cenário } \\
\hline 5 & $\begin{array}{l}\text { Calçada sem barreira urbanística, sem mudança do curso do pedestre na calçada; largura igual } \\
\text { ou superior a 1,5 m }\end{array}$ \\
\hline 4 & $\begin{array}{l}\text { Calçada sem barreira urbanística, sem mudança do curso do pedestre na calçada; largura igual } \\
\text { ou superior a 1,2 m }\end{array}$ \\
\hline 3 & $\begin{array}{l}\text { Calçada reduzida por barreira urbanística, sem mudança do curso do pedestre na calçada; } \\
\text { largura pouco inferior a 1,2 m em alguns pontos }\end{array}$ \\
\hline 2 & $\begin{array}{l}\text { Calçada reduzida por barreira urbanística, havendo mudanças de curso do pedestre na calçada; } \\
\text { largura inferior a 1,2 m }\end{array}$ \\
\hline 1 & $\begin{array}{l}\text { Calçada reduzida por barreira urbanística, havendo mudanças de curso do pedestre na calçada, } \\
\text { inclusive para o leito carroçável; largura inferior a 0,90 m }\end{array}$ \\
\hline 0 & $\begin{array}{l}\text { Calçada inexistente ou bloqueada por barreira urbanística, curso do pedestre realizado no leito } \\
\text { carroçável }\end{array}$ \\
\hline
\end{tabular}

\section{Quadro 8 - Sistema de pontuação para sinalização e rampas na travessia}

\begin{tabular}{|c|l|}
\hline Escore & \multicolumn{1}{|c|}{ Cenário } \\
\hline 5 & $\begin{array}{l}\text { Calçada com rampas de acesso nas intersecções com inclinação de até 8,33\% (1:12) e largura } \\
\text { mínima do rebaixamento de 1,50 m; faixa de travessia de pedestres demarcada }\end{array}$ \\
\hline 4 & $\begin{array}{l}\text { Calçada com rampas de acesso nas intersecções com inclinação de até 8,33\% (1:12) e largura } \\
\text { mínima do rebaixamento de 1,50 m; faixa de travessia de pedestres não demarcada }\end{array}$ \\
\hline 3 & $\begin{array}{l}\text { Calçada com rampas de acesso nas intersecções com inclinação superior a 8,33\% (1:12) e/ou } \\
\text { largura do rebaixamento inferior a 1,50 m, porém com condição de utilização por pessoa em } \\
\text { cadeira de rodas e PMR; faixa de travessia de pedestres demarcada }\end{array}$ \\
\hline 2 & $\begin{array}{l}\text { Calçada com rampas de acesso nas intersecções com inclinação superior a 8,33\% (1:12) e/ou } \\
\text { largura do rebaixamento inferior a 1,50 m, porém com condição de utilização por pessoa em } \\
\text { cadeira de rodas e PMR; faixa de travessia de pedestres não demarcada }\end{array}$ \\
\hline 1 & Calçadas sem rampas de acesso nas intersecções utilizáveis; faixa de pedestres demarcada \\
\hline 0 & $\begin{array}{l}\text { Calçadas sem rampas de acesso nas intersecções utilizáveis; faixa de pedestres não } \\
\text { demarcada }\end{array}$ \\
\hline
\end{tabular}

\section{Quadro 9 - Sistema de pontuação para inclinação longitudinal}

\begin{tabular}{|c|l|}
\hline Escore & \multicolumn{1}{|c|}{ Cenário } \\
\hline 5 & Calçada com inclinação longitudinal máxima de $3 \%$ \\
\hline 4 & Calçada com inclinação longitudinal máxima de $5 \%$ \\
\hline 3 & Calçada com inclinação longitudinal máxima de $6,25 \%$ \\
\hline 2 & Calçada com inclinação longitudinal máxima de $8,33 \%$ \\
\hline 1 & Calçada com inclinação longitudinal máxima de $12,5 \%$ \\
\hline 0 & Calçada com inclinação longitudinal superior a 12,5\% \\
\hline
\end{tabular}

\section{Quadro 10 - Sistema de pontuação para inclinação transversal}

\begin{tabular}{|c|l|}
\hline Escore & \multicolumn{1}{|c|}{ Cenário } \\
\hline 5 & Calçada com inclinação transversal máxima de $3 \%$ \\
\hline 4 & Calçada com inclinação transversal máxima de 5\% \\
\hline 3 & Calçada com inclinação transversal máxima de $6,25 \%$ \\
\hline 2 & Calçada com inclinação transversal máxima de $8,33 \%$ \\
\hline 1 & Calçada com inclinação transversal máxima de $12,5 \%$ \\
\hline 0 & Calçada com inclinação transversal superior a 12,5\% \\
\hline
\end{tabular}


Quadro 11 - Sistema de pontuação para desníveis

\begin{tabular}{|c|l|}
\hline Escore & \multicolumn{1}{|c|}{ Cenário } \\
\hline 5 & Calçada sem desnível \\
\hline 4 & Calçada com desnível de até $5 \mathrm{~mm}$ \\
\hline 3 & Calçada com desnível entre $5 \mathrm{~mm}$ e $20 \mathrm{~mm}$ \\
\hline 2 & Calçada com degrau entre $20 \mathrm{~mm}$ e $75 \mathrm{~mm}$ \\
\hline 1 & Calçada com degrau entre $75 \mathrm{~mm}$ e $180 \mathrm{~mm}$ \\
\hline 0 & Calçada com degrau superior a $180 \mathrm{~mm}$ \\
\hline
\end{tabular}

\section{Coleta de dados}

Realizou-se uma pesquisa de opinião pelo pesquisador por meio da aplicação de questionários à população sãotomeense. Inicialmente, de modo a entender 0 perfil dos entrevistados, foram solicitadas informações pessoais referentes à faixa etária, ao grau de instrução, ao sexo, à frequência do uso das calçadas, bem como se o munícipe era uma pessoa com deficiência ( $\mathrm{PCD}$ ) ou uma pessoa com mobilidade reduzida (PMR).

Então, ao entrevistado, no papel de julgador, eram apresentadas as variáveis presentes nos grupos de qualidade do espaço e de acessibilidade para sua apreciação, e ele deveria ordenar os fatores apresentados para cada um dos grupos em ordem crescente de importância, conforme entendesse pertinente.

O Quadro 12 expressa as descrições das variáveis apresentadas aos usuários para os grupos de qualidade do espaço e de acessibilidade.

Caso o munícipe ficasse com dúvidas quanto ao que representava a variável, era dada uma explicação em linguagem mais acessível, com uso, inclusive, de exemplos práticos de ocorrências na própria cidade. Porém, os exemplos eram utilizados com prudência, de modo a não influenciar o entrevistado em suas respostas.

A aplicação dos questionários foi direcionada a toda a população urbana. Definiu-se que o entrevistado deveria ser maior de idade para dar maior confiabilidade aos dados levantados, bem como evitar a necessidade da presença de um responsável legal.

A pesquisa foi realizada durante 20 dias, de 2 de fevereiro até 31 de março de 2016, nas áreas públicas da urbe, com abordagem aleatória. Buscou-se a aplicação de questionários em todos os bairros, de modo a contemplar a opinião dos moradores de toda a cidade.

Visto que o procedimento adotado corresponde a uma pesquisa com seres humanos, foram contemplados os procedimentos preconizados pela
Resolução no 466 de 12 de dezembro de 2012 do Conselho Nacional de Saúde (CONSELHO..., 2013). A aprovação do projeto de pesquisa pelo Comitê de Ética em Pesquisa (CEP) da Universidade Estadual de Maringá (CAAE: 52570616.9.0000.0104) se deu por meio da emissão do Parecer Consubstanciado $\mathrm{n}^{\mathrm{0}}$ 1.409.605.

\section{Tamanho da amostra}

Realizou-se uma amostragem aleatória simples da população urbana (universo amostral), sendo utilizadas as Equações 1 e 2 para cálculo do tamanho da amostra. Para fins deste estudo, propõese a utilização de margem de erro de 5 pontos e margem de confiança de $95 \%$.

$n_{0}=\frac{\left(Z_{\alpha / 2}\right)^{2}}{4 . e^{2}}$

Onde:

$\mathrm{n}_{0}$ é o valor estimado do tamanho total da amostra;

$Z \alpha / 2$ é o quantil da distribuição normal com nível de confiança $(1-\alpha) \%$; e

e é o erro máximo da estimativa.

$n=\frac{N \times n_{0}}{N+n_{0}-1}$

Onde:

n é o tamanho amostral; e

$\mathrm{N}$ é o tamanho do universo.

\section{Ponderação das variáveis de qualidade do espaço e acessibilidade}

Para verificar a percepção das pessoas quanto à importância dos fatores, utilizou-se o método dos intervalos sucessivos, conforme Padula (1999). Segundo Ribeiro Neto (2001), nessa técnica, os entrevistados julgam as próprias variáveis avaliadas, o que oferece maior facilidade ao procedimento de aplicação. Tal método é utilizado em pesquisas psicológicas quando se deseja conhecer as distâncias entre os elementos de uma escala intervalar. 
Quadro 12 - Descrições das variáveis de qualidade do espaço e de acessibilidade fornecidas para julgamento dos entrevistados

\begin{tabular}{|c|c|c|}
\hline Grupo & Variável & Descrição \\
\hline \multirow{5}{*}{ 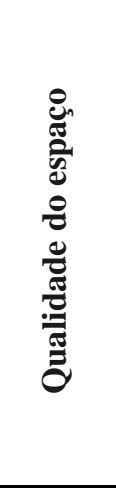 } & Segurança & $\begin{array}{l}\text { Calçada sem perigo de atropelamento pelo trânsito de carros sobre a } \\
\text { calçada para acesso às residências, comércios }\end{array}$ \\
\hline & $\begin{array}{l}\text { Construção e } \\
\text { manutenção }\end{array}$ & Calçada com piso em bom estado, sem defeitos, antiderrapante \\
\hline & Seguridade & $\begin{array}{l}\text { Calçada com presença de pedestres, policiamento e boa iluminação, } \\
\text { diminuindo o risco de ações de pessoas mal-intencionadas }\end{array}$ \\
\hline & Atratividade & $\begin{array}{l}\text { Calçada agradável ao lado de praças, parques, casas com jardins à vista, } \\
\text { comércios com vitrines atraentes }\end{array}$ \\
\hline & $\begin{array}{l}\text { Arborização da } \\
\text { calçada }\end{array}$ & $\begin{array}{l}\text { Calçada com árvores que não tenham características que possam trazer } \\
\text { riscos à saúde e segurança das pessoas, como compostos tóxicos, } \\
\text { espinhos, frutos grandes, e que não tragam danos ao ambiente por serem } \\
\text { de outras regiões }\end{array}$ \\
\hline \multirow{5}{*}{ 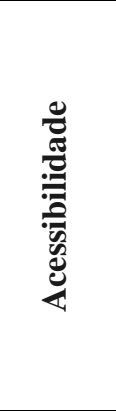 } & Largura efetiva & $\begin{array}{l}\text { Calçada livre de obstáculos, como mesas, cartazes e material de } \\
\text { construções, fazendo com que, muitas vezes, seja necessário caminhar na } \\
\text { rua }\end{array}$ \\
\hline & $\begin{array}{l}\text { Sinalização e } \\
\text { rampas }\end{array}$ & $\begin{array}{l}\text { Calçada com rampas nas esquinas e faixas de pedestres bem demarcadas } \\
\text { para atravessar a rua }\end{array}$ \\
\hline & $\begin{array}{l}\text { Inclinação } \\
\text { longitudinal }\end{array}$ & Calçada que não seja muito inclinada no sentido em que se caminha \\
\hline & $\begin{array}{l}\text { Inclinação } \\
\text { transversal }\end{array}$ & $\begin{array}{l}\text { Calçada que não seja muito inclinada no sentido do lote para o meio-fio } \\
\text { ou guia }\end{array}$ \\
\hline & Desníveis & Calçada sem desníveis ou degraus ao longo do trajeto \\
\hline
\end{tabular}

\section{Índice de serviço das calçadas e nível de serviço}

Com base na avaliação técnica e na fixação dos graus de importância das variáveis para os grupos de qualidade do espaço e de acessibilidade, são determinados dois índices. Com isso é possível analisar o desempenho desses dois fatores para as calçadas da urbe e, então, definir um índice final, obtido por meio da média aritmética simples entre os dois valores dos índices iniciais.

\section{Índices de serviço para qualidade do espaço e acessibilidade e índice final}

O Índice de Serviço das Calçadas para qualidade do espaço (ISC $\mathrm{q}_{\mathrm{q}}$ ) é definido conforme a Equação 3, e o Índice de Serviço das Calçadas para acessibilidade (ISC ), por meio da Equação 4.

$$
I S C_{q e}=p_{s} S+p_{c m} C m+p_{s e} S e+p_{a} A+p_{a c} A c
$$

Onde:

ISC $_{\mathrm{qe}}$ é o Índice de Serviço das Calçadas para qualidade do espaço;

S, Cm, Se, A, Ac são os escores atribuídos na avaliação técnica para as variáveis de segurança, construção e manutenção, seguridade, atratividade e arborização da calçada respectivamente; e $\mathrm{p}_{\mathrm{s}}, \mathrm{p}_{\mathrm{cm}}, \mathrm{p}_{\mathrm{se}}, \mathrm{p}_{\mathrm{a}}, \mathrm{p}_{\mathrm{ac}}$ são os fatores de ponderação atribuídos pelos usuários às variáveis de segurança, construção e manutenção, seguridade, atratividade e arborização da calçada respectivamente.

$I S C_{a}=p_{l e} L e+p_{s r} S r+p_{i l} I l+p_{i t} I t+p_{d} D$

Onde:

ISC $_{a}$ é o Índice de Serviço das Calçadas para acessibilidade;

Le, Sr, Il, It, D são os escores atribuídos na avaliação técnica para as variáveis de largura efetiva, sinalização e rampas, inclinação longitudinal, inclinação transversal e desníveis respectivamente; e

$\mathrm{p}_{\text {le, }}, \mathrm{p}_{\mathrm{sr}}, \mathrm{p}_{\mathrm{il}}, \mathrm{p}_{\mathrm{it}}, \mathrm{p}_{\mathrm{d}}$ são os fatores de ponderação atribuídos pelos usuários às variáveis de largura efetiva, sinalização e rampas, inclinação longitudinal, inclinação transversal e desníveis respectivamente.

Com a determinação do ISC $_{\text {qe }}$ e do ISC I $_{\mathrm{a}}$ possível obter o índice final, o Índice de Serviço das Calçadas (ISC), segundo a Equação 5.

$I S C=\frac{I S C_{q e}+I S C_{a}}{2}$

Onde ISC é o Índice de Serviço das Calçadas. 


\section{Nível de serviço}

Com valor dos índices de serviço, define-se a condição da calçada da quadra e seu respectivo nível de serviço (NS) (Quadro 13).

Entende-se que os NS mais adequados sejam A, B, $\mathrm{C}$ e $\mathrm{D}$. Os níveis A e $\mathrm{B}$ representam quadras acessíveis com alta qualidade e acessibilidade, devendo ser a meta para construção de nova calçada ou de sua reestruturação. O nível C apresenta condição adequada ao trânsito de pessoas, porém pode oferecer pouca atratividade, menos facilidades e maior esforço ao pedestre durante seu deslocamento. Já o nível D pode ser melhorado por meio de intervenções urbanas, de modo a vislumbrar o fornecimento de melhor serviço, contudo, ainda assim, sendo aceitável.

Já as condições ruins e péssimas (NS E e F) são inadequadas, devendo ser tomadas ações de requalificação da infraestrutura para que, de fato, o usuário possa realizar viagens a pé com conforto e segurança.

\section{Resultados e discussão}

Com a aplicação dos procedimentos metodológicos, executaram-se a análise técnica e as entrevistas com a população para cálculo do peso relativo das variáveis definidas, sendo possível calcular índices de serviço e determinar níveis de serviço das calçadas.

\section{Resultados da avaliação técnica das calçadas}

Foram atribuídos escores à totalidade das calçadas da cidade de São Tomé no momento da avaliação in loco, totalizando 570 quadras, o que corresponde a 47.255,8 m de calçadas. Contudo, para o parâmetro de arborização da calçada, nos casos de desconhecimento de determinada espécie, conduziu-se registro fotográfico e coleta de material botânico para posterior identificação. Em toda a cidade, inventariou-se a existência de 4.081 indivíduos, divididos em 73 espécies vegetais, sendo 1.009 destes pertencentes a 48 espécies cujas características são indesejáveis ao plantio nas calçadas.

Com a avaliação técnica, constataram-se todos os cenários das variáveis na urbe, não havendo situação não englobada nos sistemas de pontuação definidos. Com base nessa análise, ainda sem contemplar a influência das preferências populacionais, foi possível determinar a média dos escores das calçadas da cidade para cada variável dos grupos (Tabela 1).

\section{Quadro 13 - Faixas de índice de serviço com a respectiva condição e nível de serviço}

\begin{tabular}{|c|c|c|}
\hline Índice de Serviço & Condição & Nível de serviço \\
\hline 5,0 & Excelente & $\mathrm{A}$ \\
\hline 4,0 a 4,99 & Ótimo & $\mathrm{B}$ \\
\hline 3,0 a 3,99 & Bom & $\mathrm{C}$ \\
\hline 2,0 a 2,99 & Regular & $\mathrm{D}$ \\
\hline 1,0 a 1,99 & Ruim & $\mathrm{E}$ \\
\hline 0,0 a 0,99 & Péssimo & $\mathrm{F}$ \\
\hline
\end{tabular}

Tabela 1 - Atribuição de escores às variáveis dos grupos de qualidade do espaço e de acessibilidade na avaliação técnica

\begin{tabular}{|c|c|c|c|c|c|c|c|c|}
\hline \multirow{2}{*}{$\begin{array}{c}\text { Grup } \\
\text { o }\end{array}$} & \multirow{2}{*}{ Variável } & \multicolumn{6}{|c|}{ Número de atribuições do escore } & \multirow{2}{*}{$\begin{array}{c}\text { Média de } \\
\text { escores }\end{array}$} \\
\hline & & 5 & 4 & 3 & 2 & 1 & $\mathbf{0}$ & \\
\hline \multirow{5}{*}{ 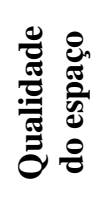 } & Segurança & 27 & 203 & 7 & 3 & 328 & 2 & 2,28 \\
\hline & Construção e manutenção & 53 & 72 & 13 & 59 & 90 & 283 & 1,40 \\
\hline & Seguridade & 60 & 42 & 126 & 91 & 105 & 146 & 1,99 \\
\hline & Atratividade & 5 & 66 & 185 & 17 & 150 & 147 & 1,80 \\
\hline & Arborização da calçada & 229 & 160 & 95 & 20 & 36 & 30 & 3,76 \\
\hline \multirow{5}{*}{ 章 } & Largura efetiva & 45 & 50 & 16 & 48 & 87 & 324 & 1,15 \\
\hline & Sinalização e rampas & 39 & 41 & 45 & 14 & 63 & 368 & 1,03 \\
\hline & Inclinação longitudinal & 61 & 59 & 69 & 33 & 30 & 318 & 1,48 \\
\hline & Inclinação transversal & 73 & 66 & 61 & 41 & 17 & 312 & 1,60 \\
\hline & Desníveis & 46 & 22 & 38 & 27 & 18 & 419 & 0,88 \\
\hline
\end{tabular}


Para o grupo de qualidade do espaço, tem-se a melhor média de pontuações para a variável arborização da calçada (3,76), bem como o maior número de aplicações da pontuação máxima (229). Destaca-se que, ao excluírem-se os cenários de pontuação 1 e 0 dessa variável, infere-se que 504 quadras, do total de 570, possuem ao menos 1 indivíduo plantado de espécie adequada. Ainda, quanto aos trabalhos de avaliação dos parâmetros desse grupo, verificou-se falta de cuidado na conservação do revestimento das calçadas, principalmente nas áreas mais periféricas da cidade, inferindo negativamente na média de pontuações para construção e manutenção, a menor média entre as variáveis do grupo $(1,40)$.

Quanto ao grupo de acessibilidade, todas as variáveis obtiveram o escore 0 como o mais recorrente. A variável inclinação transversal apresentou a maior média $(1,60)$, e desníveis, a menor $(0,88)$. Em muitos casos, as rampas podem ser soluções adequadas para a retirada dos degraus, bem como para a regularização das soleiras ajustadas para acesso dos veículos.

\section{Resultados da pesquisa de opinião}

Inicialmente, determinou-se o tamanho da amostra conforme as Equações 1 e 2. Sendo a população residente na área urbana de 4.537 habitantes, têmse o tamanho amostral como sendo de 355 pessoas.

\section{Perfil dos entrevistados}

Com a tomada de informações pessoais foi possível traçar o perfil dos entrevistados (Tabela 2).

Chama-se a atenção para o fato de que um total de 293 pessoas declararam fazer uso das calçadas diariamente, o que demonstra quão importante é essa infraestrutura de circulação para a mobilidade da cidade. Do total de entrevistados, 95 apresentaram alguma dificuldade de locomoção, sendo 11 PcD e outros 84 PMR, compreendendo idosos $(n=51)$, pessoas com criança de colo $(n=14)$, pessoas obesas $(n=7)$, pessoas conduzindo carrinho de bebês $(n=6)$ e gestantes $(n=6)$.

\section{Determinação da importância relativa das variáveis de qualificação}

Conhecendo-se o número de respostas dos entrevistados, executaram-se os procedimentos estatísticos visando à obtenção do grau de importância relativo dos parâmetros para os grupos de qualidade do espaço e de acessibilidade (Tabela 3).

\section{Tabela 2 - Perfil dos entrevistados}

\begin{tabular}{|c|c|c|c|}
\hline \multicolumn{2}{|l|}{ Faixa etária } & \multicolumn{2}{|c|}{ Grau de instrução } \\
\hline $\begin{array}{l}\text { De } 18 \text { a } 30 \text { anos - } \\
\text { De } 31 \text { a } 40 \text { anos - } \\
\text { De } 41 \text { a } 50 \text { anos - } \\
\text { De } 51 \text { a } 60 \text { anos - } \\
\text { Acima de } 60 \text { anos - }\end{array}$ & & $\begin{array}{r}\text { Sem } \\
1^{\circ} \text { ao } 4^{\circ} \text { ano dc } \\
5^{\circ} \text { ao } 9^{\circ} \text { ano do } \\
\text { Ensino médio (cc } \\
\text { Ensino superior (c }\end{array}$ & $\begin{array}{l}\text { olaridade }-2,3 \% \\
\text { sino fundamental - 15,5\% } \\
\text { sino fundamental - 15,2\% } \\
\text { leto ou incompleto) - 38,6\% } \\
\text { pleto ou incompleto) }-28,6 \%\end{array}$ \\
\hline Sexo & & uldade de locomoção & Frequência de uso \\
\hline $\begin{array}{c}\text { Masculino - 49,3\% } \\
\text { Feminino - 50,7\% }\end{array}$ & & $\begin{array}{l}\text { PcD - 3,1\% } \\
\text { PMR - 23,7\% } \\
\text { dificuldade }-73,2 \%\end{array}$ & $\begin{array}{c}\text { Diariamente }-82,5 \% \\
4 \text { a } 6 \text { vezes por semana }-8,7 \% \\
1 \text { a } 3 \text { vezes por semana }-7,9 \% \\
\text { Quase nunca }-0,8 \%\end{array}$ \\
\hline
\end{tabular}

Tabela 3 - Respostas dos entrevistados e graus de importância relativa para os grupos de qualidade do espaço e de acessibilidade

\begin{tabular}{|c|c|c|c|c|c|c|c|}
\hline \multirow{2}{*}{ Grupo } & \multirow{2}{*}{ Variável } & \multicolumn{5}{|c|}{ Respostas por nível de importância } & \multirow{2}{*}{$\begin{array}{c}\text { Importância } \\
\text { relativa }\end{array}$} \\
\hline & & 1 & 2 & 3 & 4 & 5 & \\
\hline \multirow{5}{*}{ 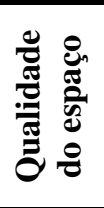 } & Segurança & 33 & 17 & 70 & 94 & 141 & 0,12 \\
\hline & Construção e manutenção & 177 & 78 & 51 & 27 & 22 & 0,31 \\
\hline & Seguridade & 80 & 163 & 64 & 41 & 7 & 0,29 \\
\hline & Atratividade & 35 & 34 & 67 & 85 & 134 & 0,13 \\
\hline & Arborização da calçada & 30 & 63 & 103 & 108 & 51 & 0,15 \\
\hline \multirow{5}{*}{ 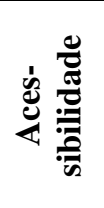 } & Largura efetiva & 167 & 89 & 41 & 40 & 18 & 0,31 \\
\hline & Sinalização e rampas & 101 & 135 & 68 & 25 & 26 & 0,26 \\
\hline & Inclinação longitudinal & 7 & 22 & 39 & 87 & 200 & 0,11 \\
\hline & Inclinação transversal & 18 & 38 & 77 & 148 & 74 & 0,13 \\
\hline & Desníveis & 62 & 71 & 130 & 55 & 37 & 0,19 \\
\hline
\end{tabular}


Para a qualidade do espaço, a população elegeu mais importante a adequabilidade das calçadas quanto à construção e manutenção (31\%), seguida dos aspectos relacionados à seguridade (29\%). Entende-se que a seguridade poderia ter maior predileção dos entrevistados no caso de cidades de maior porte, para as quais os índices de criminalidade tendem a ser mais elevados. A variável considerada menos preferida foi segurança (12\%). Sugere-se que o convívio com fluxos de veículos normalmente menores do que aqueles existentes em centros urbanos mais populosos possa trazer a sensação ao munícipe de que a situação de conflito não seja potencialmente perigosa.

Para o grupo de acessibilidade, os entrevistados julgaram mais importante a largura efetiva (31\%) e, mesmo que a maioria das pessoas entrevistadas não possuísse dificuldade em sua locomoção, sinalização e rampas foi definida como a segunda variável mais importante (26\%). Isso chama a atenção quanto à sensibilização das pessoas ao julgarem mais importante o bem-estar daqueles que têm maior dificuldade para vencer distâncias no espaço urbano. A inclinação longitudinal foi eleita como sendo menos importante (11\%). O fato de os munícipes estarem acostumados com a utilização das calçadas que acompanham ruas íngremes em diversos pontos da cidade pode concorrer para que essa seja a variável menos valorizada, haja vista a habitualidade com tal cenário.

\section{Determinação do índice de serviço das calçadas}

Para cálculo do ISC fez-se necessário definir, inicialmente, o ISC $_{q e}$ e o ISC .

\section{Determinação do $\mathrm{ISC}_{\mathrm{qe}}$ e $\mathrm{ISC}_{\mathrm{a}}$ e respectivos NS}

Realizada a análise técnica e de posse das importâncias relativas das variáveis, determinaramse, com base na Equação 3 e na Equação 4, os valores do $\mathrm{ISC}_{\mathrm{qe}}$ e do $\mathrm{ISC}_{\mathrm{a}}$ respectivamente à totalidade das calçadas de São Tomé. A Tabela 4 apresenta o número de quadras e respectivos comprimentos de calçadas para cada $\mathrm{NS}_{\mathrm{qe}}$ atribuído.

Com a verificação quanto à qualidade do espaço, verifica-se aumento do número de quadras conforme o ISC $_{\text {qe }}$ decai, fazendo com que o $\mathrm{NS}_{\mathrm{qe}} \mathrm{F}$ seja o mais significativo. Agrupando-se os $\mathrm{NS}_{\mathrm{qe}} \mathrm{E}$ e $\mathrm{F}$, entendidos como inadequados, são compreendidos 54,04\% do número de quadras e 25.126,2 m do comprimento total das calçadas. Em contrapartida, 22.129,6 m de calçadas, ou 45,96\% do total de quadras, são categorizadas ao menos como regulares $\left(\mathrm{NS}_{\mathrm{qe}} \mathrm{D}\right)$. O ISC $\mathrm{ISe}_{\mathrm{q}}$ médio para as calçadas da urbe foi de 2,08, o que representa um $\mathrm{NS}_{\text {qe }} \mathrm{D}$, regular.

Nas áreas periféricas, instaladas mais recentemente, por estarem em fase de consolidação, foi comum a ocorrência de terrenos desocupados, calçadas nem ao menos construídas e disposição de materiais de construção sobre os caminhos de pedestres. Tal ambiente não condiz com os melhores cenários definidos para as variáveis de qualidade do espaço.

Quanto ao serviço para acessibilidade, a Tabela 5 apresenta uma compilação do número de quadras e comprimento para cada $\mathrm{NS}_{\mathrm{a}}$.

Tabela 4 - Número de quadras e comprimento de calçadas conforme atribuição do NS $_{\mathbf{q e}}$

\begin{tabular}{c|c|c|c}
\hline NS $_{\mathbf{q e}}$ & Condição & Número de quadras & Comprimento total (m) \\
\hline A & Excelente & 3 & 270,0 \\
B & Ótimo & 68 & $5.582,6$ \\
C & Bom & 75 & $6.225,4$ \\
D & Regular & 116 & $10.051,6$ \\
E & Ruim & 148 & $11.857,6$ \\
F & Péssimo & 160 & $13.268,6$ \\
\hline
\end{tabular}

Tabela 5 - Número de quadras e comprimento de calçadas conforme atribuição do NSa

\begin{tabular}{c|c|c|c}
\hline NS $_{\mathbf{a}}$ & Condição & Número de quadras & $\begin{array}{c}\text { Comprimento total } \\
(\mathbf{m})\end{array}$ \\
\hline A & Excelente & 3 & 255,0 \\
B & Ótimo & 25 & $2.263,1$ \\
C & Bom & 57 & $4.854,4$ \\
D & Regular & 72 & $5.709,1$ \\
E & Ruim & 75 & $5.557,7$ \\
F & Péssimo & 338 & $28.616,5$ \\
\hline
\end{tabular}


Os $\mathrm{NS}_{\mathrm{a}} \mathrm{A}, \mathrm{B}, \mathrm{C}$ e D somados totalizaram 157 quadras, atingindo $13.081,6 \mathrm{~m}$ de calçamento em quadras contínuas, entendidas como mais adequadas. Essas são montas inferiores às associadas às situações indesejáveis, as quais, englobando os $\mathrm{NS}_{\mathrm{a}} \mathrm{E}$ e $\mathrm{F}$, correspondem a $72,46 \%$ do número de quadras, o que equivale a $34.174,2 \mathrm{~m}$ de caminhos de pedestres. A cidade possui ISC $_{a}$ médio 1,16 , que corresponde a uma condição ruim $\left(\mathrm{NS}_{\mathrm{qe}} \mathrm{E}\right)$.

De fato, a precariedade das calçadas e a existência de obstáculos e ajustes para acesso aos lotes, confeccionados de maneira inadequada, foram comuns, especialmente nas áreas afastadas do centro, o que reflete diretamente em todas as variáveis negativamente.

No total, 513 quadras perfizeram ISC $_{q e}$ maior do

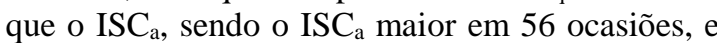
em 1 quadra os índices tiveram o mesmo valor. Essa disparidade é corroborada pelo fato de que nenhuma via apresentou ISC $_{q e}$ igual a 0,0 , tendo em vista que a existência de um espaço destinado à instalação da calçada, mesmo que inutilizável no momento, faz com que haja atribuição do escore 1 para segurança. Já para o ISC $_{a}$ foi comum a atribuição do escore 0 a todas as variáveis do grupo para uma única quadra, já que a simples existência de local para calçada não é garantia de alguma pontuação, sendo necessário que a quadra tenha alguma condição de uso desejável, conforme as variáveis solicitem. A monta de quadras que recebeu $\mathrm{ISC}_{\mathrm{a}}=0,0$ foi de 238 , $41,75 \%$ da totalidade.

\section{Determinação do ISC e NS}

Por meio da Equação 5, efetuaram-se os cálculos para determinar o ISC e respectivo NS final das quadras urbanas de São Tomé. A Tabela 6 expõe o número de quadras, com a respectiva extensão, para cada condição de serviço condicionada, com representação dos NS das calçadas conforme a Figura 3.

Tendo em vista que o cálculo do ISC resulta da média dos valores do ISC $_{q e}$ e do ISC $_{a}$, a categorização da condição péssima foi a mais significativa. As condições inadequadas, NS E e F, perfizeram $65,09 \%$ de todas as quadras (31.250,3 $\mathrm{m})$. Já os NS de A até D, por sua vez, atingiram $34,91 \%$ das quadras $(16.005,5 \mathrm{~m})$.

Tal como para o ISC $_{q e}$ e o ISC , os melhores valores foram condicionados à área central da cidade, na qual se constataram fatores como maiores dimensões, melhor conservação do pavimento, composição arbórea mais adequada e mais facilidades nas travessias. Também a existência de poucos vazios urbanos e maior atratividade, devido à paisagem melhorada, endossam o melhor serviço das quadras centrais da mancha urbana. Expandindo-se o índice para toda a cidade, o ISC foi de 1,62, o que reflete um NS E (ruim). Apenas uma quadra apresentou ISC igual a 5, máximo valor possível, equivalendo ao NS A.

Visando melhorar como um todo as viagens a pé, a melhoria dos espaços destinados a comportarem o fluxo de pedestres é fundamental. Por meio do Índice de Serviço das Calçadas é possível medir a adequabilidade dos caminhos para pedestres para serem realizadas caminhadas e, tendo sido feita a análise separada dos índices de serviço para qualidade do espaço e para acessibilidade, contemplando a opinião dos usuários, permite-se verificar quais as deficiências presentes nas calçadas urbanas de maneira mais específica, possibilitando-se condicionar uma melhor tomada de decisão sobre o planejamento dos espaços, conforme as demandas populacionais.

\section{Conclusão}

O modelo proposto apresentou aplicabilidade adequada às cidades de pequeno porte populacional, tendo em vista os resultados obtidos na cidade de São Tomé. Todas as pontuações possíveis das variáveis foram aplicadas na auditoria, assim não houve ocorrência de alguma quadra em que o cenário constatado in loco não fosse contemplado pelos sistemas de escores.

Tabela 6 - Número de quadras e comprimento de calçadas conforme atribuição do NS

\begin{tabular}{c|c|c|c}
\hline NS & Condição & Número de quadras & $\begin{array}{c}\text { Comprimento total } \\
(\mathbf{m})\end{array}$ \\
\hline A & Excelente & 1 & 95,0 \\
B & Ótimo & 32 & $2.846,4$ \\
C & Bom & 78 & $6.604,5$ \\
D & Regular & 88 & $6.459,6$ \\
E & Ruim & 106 & $9.517,9$ \\
F & Péssimo & 265 & $21.732,4$ \\
\hline
\end{tabular}


Figura 3 - Representação do nível de serviço final das quadras de São Tomé, PR

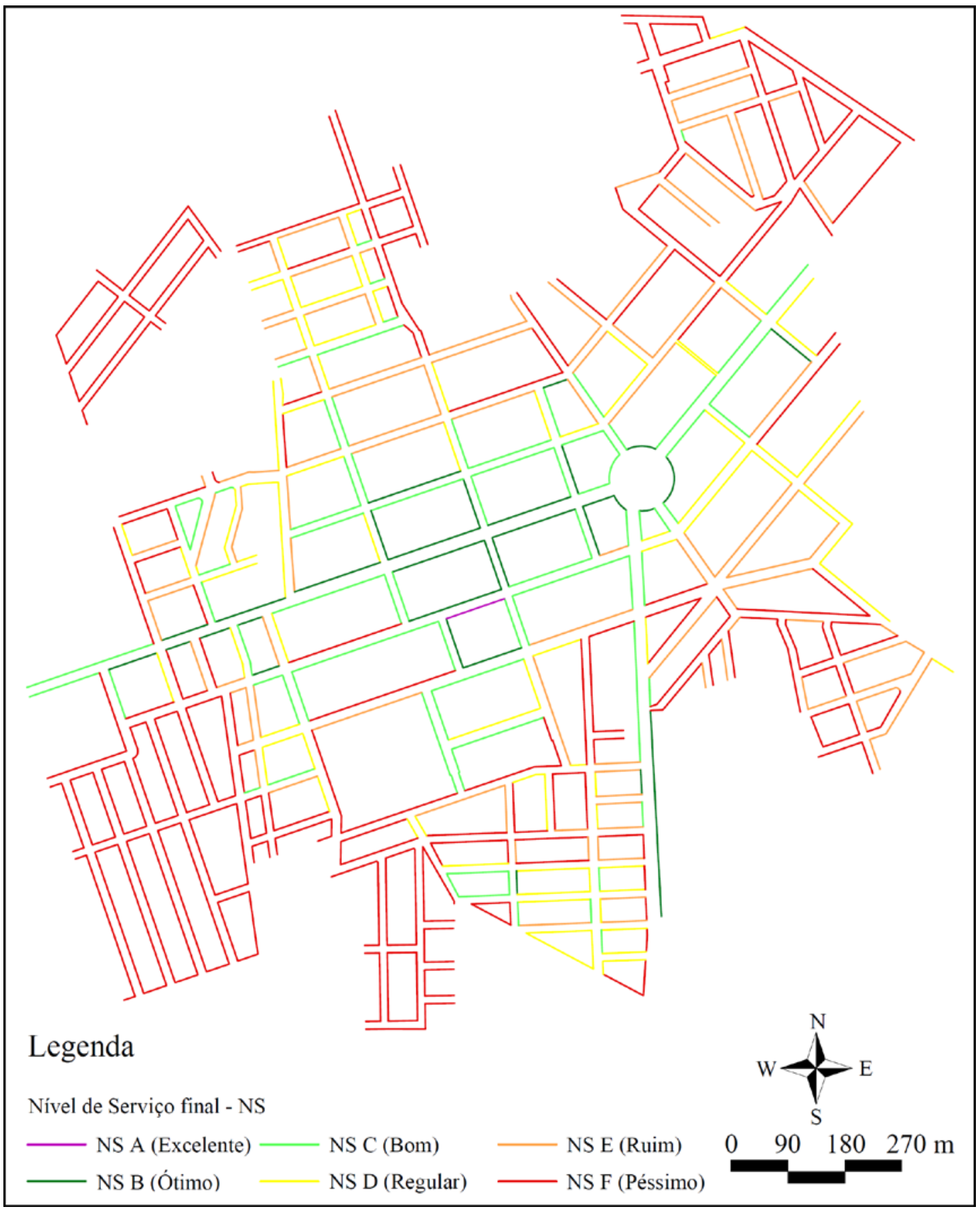

Visando à contínua melhoria do método, torna-se interessante sua aplicação em outros municípios de porte semelhante, de modo a verificar se a infraestrutura pedonal atende às demandas dos citadinos, podendo, inclusive, ser realizadas adaptações pertinentes no caso de eventuais peculiaridades urbanas de outras localidades. Ainda, destaca-se que o ISC pode ser utilizado em cidades de maior porte, contudo, para isso, diante de maiores fluxos a serem acomodados nas calçadas e da maior interação entre pedestre e veículo, devem ser realizadas adaptações.

\section{Referências}

ALVES, P. Mobilidade Urbana Sustentável e Polos Geradores de Viagens: análise da mobilidade não motorizada e do transporte público. Uberlândia, 2015. 328 f. Tese (Doutorado em Ciências Humanas) - Universidade Federal de Uberlândia, Uberlândia, 2015. 
ASADI-SHEKARI, Z.; MOEINADDINI, M.; SHAH, M. Z. Pedestrian Safety Index For Evaluating Street Facilities in Urban Areas. Safety Science, v. 74, p. 1-14, 2015.

\section{ASSOCIAÇÃO BRASILEIRA DE NORMAS}

TÉCNICAS. NBR 9050: acessibilidade a edificações, mobiliário, espaços e equipamentos urbanos. Rio de Janeiro, 2015.

\section{COMPANHIA DE ENGENHARIA DE}

TRÁFEGO. Áreas de Pedestres: conceitos.

Boletim Técnico da CET, São Paulo, v. 17, 1978.

CONSELHO NACIONAL DE SAÚDE.

Ministério da Saúde. Resolução nº 466 de 12 de dezembro de 2012. Diário Oficial da União, Brasília, DF, 13 jun. 2013.

CORREIA, S. A. V. L. Atributos de Rede Para Pedestres Com Restrições de Mobilidade em Um Modelo Para Avaliação da Acessibilidade. São Carlos, 2015. 104 f. Dissertação (Mestrado em Engenharia de Transportes) - Escola de Engenharia de São Carlos, Universidade de São Paulo, São Carlos, 2015.

DIXON, L. B. Bicycle and Pedestrian Level-ofService Performance Measures and Stardards For Congestion Management Systems.

Transportation Research Record, Washington, V. 1538, p. 1-9, 1996.

FERREIRA, M. A. G.; SANCHES, S. da P. Índice de Qualidade das Calçadas - IQC. Revista dos Transportes Públicos, São Paulo, v. 1, n. 91, p. 47-60, 2001.

FERREIRA, M. A. G.; SANCHES, S. da P. Rotas Acessíveis: formulação de um índice de acessibilidade das calçadas. In: CONGRESSO BRASILEIRO DE TRANSPORTE E TRÂNSITO, 15., Goiânia, 2015. Anais... Goiânia: 2005.

FRUIN, J. J. Designing For Pedestrians: a level-ofservice concept. Highway Research Record, v. 355, p. 1-15, 1971.

INSTITUTO BRASILEIRO DE GEOGRAFIA E ESTATÍSTICA. Atlas do Censo Demográfico 2010. Rio de Janeiro: IBGE, 2013.

INSTITUTO BRASILEIRO DE GEOGRAFIA E ESTATÍSTICA. Divisão Regional do Brasil em Regiões Geográficas Imediatas e Regiões Geográficas Intermediárias 2017. Rio de Janeiro: IBGE, 2017.

INSTITUTO BRASILEIRO DE GEOGRAFIA E ESTATÍSTICA. IBGE Cidades, São Tomé - PR. Rio de Janeiro, 2018. Disponível em: $<$ https://cidades.ibge.gov.br/brasil/pr/saotome/panorama> Acesso em: 7 abr. 2018.
INSTITUTO DE PESQUISA ECONÔMICA

APLICADA. Atlas da Violência 2016:

caracterização, tendências e custos para a sociedade. Brasília: IPEA, 2016.

INSTITUTO PARANAENSE DE

DESENVOLVIMENTO ECONÔMICO E

SOCIAL. Relação dos Municípios do Estado

Ordenados Segundo as Mesorregiões e as

Microrregiões Geográficas do IBGE - Paraná.

Curitiba: Ipardes, 2012.

KADALI, R. B.; VEDAGIRI, P. Evaluation of Pedestrian Crosswalk Level of Service (LOS) in Perspective of Type of Land-Use. Transportation Research Part A, v. 73, p. 113-124, 2015.

KEPPE JÚNIOR, C. L. G. Formulação de Um Indicador de Acessibilidade das Calçadas e Travessias. Pós, v. 15, n. 24, p. 144-161, 2007.

KHISTY, C. J. Evaluation of Pedestrian Facilities: beyond the level-of-service concept.

Transportation Research Record, Washington, n. 1438, p. 45-50, 1994.

KOCKELMAN, K. et al. The Nature of ADA's Sidewalk Cross-Slopes Requirements: a review of the literature. Transportation Research Record, Washington, v. 1705, p. 53-60, 2000.

MORI, M.; TSUKAGUCHI, H. A New Method For the Evaluation of Level of Service in Pedestrian Facilities. Transportation Research A, v. 21 A, n. 3, p. 223-234, 1987.

OEDA, Y.; SUMI, T.; VANDEBONA, U. Wheelchair User Perception of Road Roughness. In: AUSTRALASIAN TRANSPORT RESEARCH FORUM, 26., Wellington, 2003. Proceedings... Wellington: ATRF, 2003.

PADULA, F. R. de G. Qualidade de Pavimentos e Auditoria. São Carlos, 1999. 73 f. Dissertação (Mestrado em Engenharia Civil) - Escola de Engenharia de São Carlos, Universidade de São Paulo, São Carlos, 1999.

POLUS, A.; SCHOFER, J. L.; USHPIZ, A. Pedestrian Flow and Level of Service. Journal of Transportation Engineering, v. 109, p. 46-56, 1983.

\section{RIBEIRO NETO, A. A. A. Contribuição à} Avaliação de Transporte Urbano Por Ônibus. São Carlos, 2001. 81 f. Dissertação (Mestrado em Engenharia Civil) - Escola de Engenharia de São Carlos, Universidade de São Paulo, São Carlos, 2001.

SARKAR, S. Determination of Service Levels For Pedestrians, With European Examples.

Transportation Research Record, Washington, v. 1405, p. 35-42, 1993. 
TALAVERA-GARCIA, R.; SORIA-LARA, J. A. Q-PLOS, Developing an ALTERNATIVE walking Index: a method based on urban design quality.

Cities, Washington, v. 45, p. 7-17, 2015.

TRANSPORTATION RESEARCH BOARD.

Highway Capacity Manual 2010. Transportation Research Board, The National Academies,

Washington, 2010.

\section{Agradecimentos}

Os autores agradecem à Coordenação de Aperfeiçoamento de Pessoal de Nível Superior (CAPES) pelo apoio financeiro à execução desta pesquisa.

\section{Otavio Henrique da Silva}

Departamento de Engenharia Civil, Centro de Ciências Exatas e de Tecnologia | Universidade Federal de São Carlos | Rodovia Washington Luis, km 235, Jardim Guanabara | São Carlos - SP - Brasil | CEP 13565-905 | Tel.: (44) 99942-0476| E-mail: silva.oh@outlook.com

\section{Generoso De Angelis Neto}

Departamento de Engenharia Civil, Centro de Tecnologia | Universidade Estadual de Maringá | Av. Colombo, 5.790, Zona 07 | Maringá PR - Brasil | CEP 87020-900 | Tel.: (44) 3011-4322 | E-mail: ganeto@uem.br

\section{Revista Ambiente Construído}

Associação Nacional de Tecnologia do Ambiente Construído

Av. Osvaldo Aranha, 99 - 3o andar, Centro

Porto Alegre - RS - Brasil

CEP $90035-190$

Telefone: +55 (51) 3308-4084

Fax: +55 (51) 3308-4054

www. seer. ufrgs. br/ ambienteconstruido

E-mail: ambienteconstruido@ufrgs.br

(c) (i) This is an open-access article distributed under the terms of the Creative Commons Attribution License. 